\title{
Lung-protective mechanical ventilation for patients undergoing abdominal laparoscopic surgeries: a randomized controlled trial
}

Trung Kien Nguyen ${ }^{1} \mathbb{D}$, Viet Luong Nguyen ${ }^{2} \mathbb{D}$, Truong Giang Nguyen ${ }^{3} \mathbb{D}$, Duc Hanh Mai ${ }^{4} \mathbb{D}$,

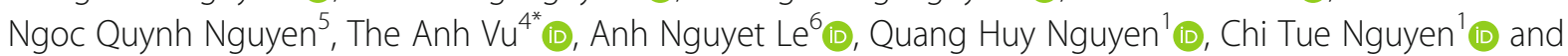
Dang Thu Nguyen ${ }^{4}$

\begin{abstract}
Background: Pneumoperitoneum and Trendelenburg position in laparoscopic surgeries could contribute to postoperative pulmonary dysfunction. In recent years, intraoperative lung-protective mechanical ventilation (LPV) has been reportedly able to attenuate ventilator-induced lung injuries (VILI). Our objectives were to test the hypothesis that LPV could improve intraoperative oxygenation function, pulmonary mechanics and early postoperative atelectasis in laparoscopic surgeries.

Methods: In this randomized controlled clinical trial, 62 patients indicated for elective abdominal laparoscopic surgeries with an expected duration of greater than $2 \mathrm{~h}$ were randomly assigned to receive either lung-protective ventilation (LPV) with a tidal volume (Vt) of $7 \mathrm{ml} \mathrm{kg}^{-1}$ ideal body weight (IBW), $10 \mathrm{cmH}_{2} \mathrm{O}$ positive end-expiratory pressure (PEEP) combined with regular recruitment maneuvers (RMs) or conventional ventilation (CV) with a Vt of $10 \mathrm{ml} \mathrm{kg}^{-1} \mathrm{IBW}, \mathrm{O} \mathrm{cmH}_{2} \mathrm{O}$ in PEEP and no RMs. The primary endpoints were the changes in the ratio of $\mathrm{PaO}_{2}$ to $\mathrm{FiO}_{2}(\mathrm{P} / \mathrm{F})$. The secondary endpoints were the differences between the two groups in $\mathrm{PaO}_{2}$, alveolar-arterial oxygen gradient $\left(\mathrm{A}-\mathrm{aO}_{2}\right)$, intraoperative pulmonary mechanics and the incidence of atelectasis detected on chest $\mathrm{x}$-ray on the first postoperative day.

Results: In comparison to CV group, the intraoperative $\mathrm{P} / \mathrm{F}$ and $\mathrm{PaO}_{2}$ in $\mathrm{LPV}$ group were significantly higher while the intraoperative $A-a O_{2}$ was clearly lower. $C_{\text {dyn }}$ and $C_{\text {stat }}$ at all the intraoperative time points in LPV group were significantly higher compared to CV group $(p<0.05)$. There were no differences in the incidence of atelectasis on day one after surgery between the two groups.
\end{abstract}

Conclusions: Lung protective mechanical ventilation significantly improved intraoperative pulmonary oxygenation function and pulmonary compliance in patients experiencing various abdominal laparoscopic surgeries, but it could not ameliorate early postoperative atelectasis and oxygenation function on the first day after surgery.

Trial registration: https://www.clinicaltrials.gov/identifier: NCT04546932 (09/05/2020).

Keywords: Lung-protective ventilation, Low tidal volume, Recruitment maneuvers, Positive end-expiratory pressure

\footnotetext{
* Correspondence: qy.theanh@gmail.com

${ }^{4}$ Department of Anesthesia and Pain Medicine, 103 Military Hospital, Vietnam Military Medical University, Hanoi, Vietnam

Full list of author information is available at the end of the article
}

\section{$\triangle B M C$}

(c) The Author(s). 2021 Open Access This article is licensed under a Creative Commons Attribution 4.0 International License, which permits use, sharing, adaptation, distribution and reproduction in any medium or format, as long as you give appropriate credit to the original author(s) and the source, provide a link to the Creative Commons licence, and indicate if changes were made. The images or other third party material in this article are included in the article's Creative Commons licence, unless indicated otherwise in a credit line to the material. If material is not included in the article's Creative Commons licence and your intended use is not permitted by statutory regulation or exceeds the permitted use, you will need to obtain permission directly from the copyright holder. To view a copy of this licence, visit http://creativecommons.org/licenses/by/4.0/ The Creative Commons Public Domain Dedication waiver (http://creativecommons.org/publicdomain/zero/1.0/) applies to the data made available in this article, unless otherwise stated in a credit line to the data. 


\section{Background}

Laparoscopy has been widely used in surgical treatment because of its advantages such as minimal invasiveness, better cosmetic outcome, and shorter length of hospital stay. However, the effects of pneumoperitoneum and Trendelenburg position on pulmonary function in laparoscopy have posed particular concerns. Pneumoperitoneum and Trendelenburg position could contribute to atelectasis formation [1], particularly in dependent regions [2] and elevate mechanical stress in pulmonary parenchyma [3], triggering significant perioperative pulmonary dysfunction. In addition, general anesthesia with mechanical ventilation, by decreasing end-expiratory lung volume (EELV) and forming atelectasis, lead to a deterioration in respiratory mechanics and gas exchange $[4,5]$. Especially, ventilation patterns with high tidal volumes should overdistend noninjured lungs, thereby activating a local inflammation and coagulation reaction $[6,7]$.Furthermore, zero-positive end-expiratory pressure or low levels of positive end-expiratory pressure (PEEP) could induce repetitive collapse and reopening of the alveoli, which ultimately result in an inflammatory injury [8].

In recent years, intraoperative lung-protective mechanical ventilation (LPV) has been reportedly able to attenuate ventilator-induced lung injuries (VILI) [9] by employing a low tidal volume (Vt) [10], an appropriate level of PEEP [11], and recruitment maneuvers (RMs) [12]. The goals of these interventions are to minimize alveolar overdistention, to prevent repeated collapse and reopening of alveoli and to reduce atelectasis.

There have been several randomized controlled clinical trials (RCTs) that compared a protective strategy of ventilation with a conventional strategy in various surgical procedures such as cardiac surgery [13], open abdominal surgery [14-17], spinal surgery [12], or thoracic surgery $[18,19]$. We tested the hypothesis that the lungprotective ventilation strategy including a low tidal volume, an appropriate level of PEEP and periodic recruitment maneuvers could improve intraoperative oxygenation function, pulmonary mechanics, and early postoperative atelectasis.

\section{Materials and methods}

We performed a randomized controlled trial at Vietnam National Cancer Hospital from January 2020 to July 2020. The trial protocol was approved by the Medical Ethics Committee of Vietnam National Cancer Hospital and Vietnam Military Medical University (QĐ-HVQY 264-2020; chairperson Prof Truong Giang Nguyen; on 10 January 2020). The protocol was also registered in https://www.clinicaltrials.gov/ (Protocol Registration and Results System NCT04546932 on September 5th 2020). Also of important, written informed consent was obtained from all patients before inclusion.

\section{Participants}

Inclusion criteria were those older than 18 years of age, planned to undergo elective abdominal laparoscopic surgeries with an expected duration of greater than $2 \mathrm{~h}$, classified as American Society of Anesthesiologists (ASA) physical status II-III and had a body mass index (BMI) less than $30 \mathrm{~kg} \mathrm{~m}^{-2}$. Patients were excluded from the study if they met at least one of these following criteria: refusal to participate in the study, preexisting significant cardiac or pulmonary comorbidities (for instance, heart failure, intractable shock, chronic obstructive pulmonary disease, asthma, pulmonary infection, bronchiectasis, pulmonary metastases), preexisting abnormalities on chest X-ray or spirometry, a history of neuromuscular disease, liver cirrhosis (Child B or C), or chronic renal failure with hemodialysis, and the need to continue prolonged mechanical ventilation after surgery.

\section{Randomization and blinding technique}

Participants were randomly assigned to receive either the lung-protective ventilation (LPV group) or the conventional ventilation (CV group) at a ratio of $1: 1$. The randomization was performed by a physician who did not get involved in the study, using the $\mathrm{R}$ program with the "runif", "as.integer", "int" and "replace" functions. As a result, a list of random numbers was created in each group. The patients, according to their orders of hospital registration, were numbered and then allocated into the group containing their numbers. The intervention protocols were stored in sealed, opaque numbered envelopes. An anesthesiologist who was not involved in the study opened the envelopes and then set the ventilator in accordance with the protocols in the envelopes. Another anesthetist who was in charge of the patients collected data during surgery. Calculated parameters was processed by the physician responsible for analyzing statistics after data collection. The patients and the surgeons taking part in the procedures were not informed of the ventilator setting. Physicians in post-anesthesia care unit who were not responsible for intraoperative care carried out the postoperative evaluation. The postoperative chest X-ray was analyzed by a radiologist who was not involved in the study.

\section{Standard procedure}

All patients fasted for $12 \mathrm{~h}$ before the procedure but were allowed to drink water until $2 \mathrm{~h}$ prior to surgery. In the operating room, a radial arterial cannula was inserted to monitor invasive blood pressure, to collect blood gas sample, and to measure the pulse pressure variation (PPV) index in order to guide intraoperative fluid therapy. An epidural catheter was also inserted for postoperative analgesia. 
All patients received intravenous fentanyl $2 \mu \mathrm{g} \mathrm{kg}^{-1}$, lidocaine $40 \mathrm{mg}$, propofol $2 \mathrm{mg} \mathrm{kg}^{-1}$, and rocuronium 1 $\mathrm{mg} \mathrm{kg}^{-1}$, for induction. Anesthesia was maintained using sevoflurane of which the concentration was adjusted to achieve the end-tidal concentration within the range of 1.4-1.8 in oxygen and to keep the PRST score (pressure, rate, sweating, tears) less than 3 . If the PRST score was greater than 3 , then an additional bolus dose of $0.5 \mathrm{mg}$ $\mathrm{kg}^{-1}$ propofol and $1 \mu \mathrm{gg}^{-1}$ fentanyl was injected along with increasing sevoflurane concentration. On the contrary, if signs of deep anesthesia were presented (PRST score $=0$, blood pressure decreased by more than $20 \%$ of the baseline values, bradycardia), then the sevoflurane concentration was decreased and $100 \mathrm{ml}$ of ringer lactate solution was rapidly infused within $2 \mathrm{~min}$. If the blood pressure was still lower than $20 \%$ of the baseline value in spite of these above-mentioned steps, a bolus dose of 100-200 $\mu \mathrm{g}$ phenylephrine was added. Rocuronium was continuously infused at the rate of $10 \mu \mathrm{g} \mathrm{kg}^{-1} \mathrm{~min}^{-1}$. The solution of bupivacaine $0.1 \%$ combined with fentanyl $2 \mu \mathrm{g} \mathrm{ml}^{-1}$ was infused via the epidural catheter at the rate of $5 \mathrm{ml} \mathrm{h}^{-1}$ after a loading dose of $5 \mathrm{ml}$ prior to skin incision. The pneumoperitoneum was implemented by $\mathrm{CO}_{2}$ insufflation at a pressure of $12 \mathrm{mmHg}$ with room temperature in all patients. The intraoperative fluid was managed based on the goal-directed fluid therapy with a crystalloid solution. In brief, no additional fluid was provided if PPV was lower than $10 \%$, otherwise, bolus doses of $250 \mathrm{ml}$ ringer lactate solution were given over 10-15 min. After each bolus dose, PPV was re-assessed and further bolus doses were administered until PPV was lower than $10 \%$ [20-22].

Ondansetron $8 \mathrm{mg}$ was injected intravenously $30 \mathrm{~min}$ before the end of surgery to prevent postoperative nausea and vomiting. The neuromuscular blockade was reversed using intravenous neostigmine $40-60 \mu \mathrm{g} \mathrm{kg}^{-1}$ combined with atropine $0.5 \mathrm{mg}$. Patients were extubated when they met the extubation criteria (spontaneous tidal volume $>6 \mathrm{ml} \mathrm{kg}^{-1}$ and respiratory rate $=12-20$ breath $\mathrm{min}^{-1}, \mathrm{SpO}_{2}>95 \%$, normocarbia, body temperature > $35^{\circ} \mathrm{C}$, positive gag reflexes and ability to follow a verbal command, hemodynamic stability without vasopressor support and ability to lift their heads and hold for $5 \mathrm{~s}$ ) [23]. Postoperative epidural analgesia for $48 \mathrm{~h}$ was conducted using bupivacaine $0.1 \%$ combined with fentanyl $2 \mu \mathrm{g} \mathrm{ml}^{-1}$ at an infusion rate of $5-10 \mathrm{ml} \mathrm{h}^{-1}$ to maintain a visual analogue scale (VAS) score $<3$.

\section{Ventilation protocol}

Mechanical ventilation protocol was performed on the anesthesia machine GE healthcare carestation 620. The patient's ideal body weight was predefined according to these formulas: $45.5+0.91 \times[$ height $(\mathrm{cm})-152.4]$ for women or $50+0.91 \times[$ height $(\mathrm{cm})-152.4]$ for men. In both two groups, mechanical ventilation was set up at the volume-controlled mode, the inspiration to expiration ratio of 1:2. $\mathrm{FiO}_{2}$, after being kept at 1.0 in the induction period, was maintained at 0.4 until extubation. Respiratory rate, starting with 18 breaths $\mathrm{min}^{-1}$, was then modulated to keep the end-tidal carbon dioxide $\left(\mathrm{EtCO}_{2}\right)$ in the normal range of $35-40 \mathrm{mmHg}$. In CV group, the tidal volume was set at $10 \mathrm{ml} \mathrm{kg}^{-1} \mathrm{IBW}$ without PEEP and RM. In contrast, in LPV group, patients were provided with a tidal volume of $7 \mathrm{ml} \mathrm{kg}^{-1} \mathrm{IBW}$ and an intraoperative $10 \mathrm{cmH}_{2} \mathrm{O}$ PEEP. Simultaneously, in LPV group, alveoli were recruited applying a stepwise increase in PEEP (from 4 to $10 \mathrm{cmH}_{2} \mathrm{O}$ for 3 breaths, 10 to $15 \mathrm{cmH}_{2} \mathrm{O}$ for 3 breaths, and 15 to $20 \mathrm{cmH}_{2} \mathrm{O}$ for 10 breaths) with maximum PIP (Peak Inspiratory Pressure) of $50 \mathrm{cmH}_{2} \mathrm{O}$ [24]. The recruitment maneuvers were performed right after intubation, 30 min after $\mathrm{CO}_{2}$ insufflation, then every hour, and finally before extubation. During anesthesia, a plateau pressure of no more than $30 \mathrm{cmH}_{2} \mathrm{O}$ was targeted in each group.

\section{Data source and collection}

The demographic characteristics including age, gender, height, weight, BMI, ASA physical status and history of coexisting diseases and smoking were recorded. Vital signs (heart rate, blood pressure, $\mathrm{SpO}_{2}, \mathrm{EtCO}_{2}$, core temperature) were also documented every $15 \mathrm{~min}$ throughout the surgery. The volume of intravenous fluid (crystalloid, colloid solution), the volume of blood loss and urine output; total given dose of anesthetics, fentanyl, and muscle relaxant, were recorded as well. Arterial blood samples were withdrawn from the radial arterial cannula for blood gas analysis before induction, $1 \mathrm{~h}$ after pneumoperitoneum, and day one after operation. The ratio of $\mathrm{P} / \mathrm{F}$ and the alveolar-arterial oxygen gradient $\left(\mathrm{A}-\mathrm{aO}_{2}\right)$ was calculated respectively as $\mathrm{P} / \mathrm{F}=$ $\mathrm{PaO}_{2} / \mathrm{FiO}_{2}$ and $\mathrm{A}-\mathrm{aO}_{2}=\left(\mathrm{PB}-\mathrm{PH}_{2} \mathrm{O}\right) \times \mathrm{FiO}_{2}-\mathrm{PaCO}_{2} / \mathrm{R}-$ $\mathrm{PaO}_{2}$ where $\mathrm{PB}$ (atmospheric pressure) is $760 \mathrm{mmHg}$, $\mathrm{PH}_{2} \mathrm{O}$ (saturated vapor pressure at room temperature) is $47 \mathrm{mmHg}$, and the $\mathrm{R}$ (respiration quotient) is 0.8 . The dynamic compliance $\left(C_{\text {dyn }}\right)$ was measured directly on the ventilator, and the static compliance $\left(\mathrm{C}_{\text {stat }}\right)$ was calculated in accordance with the pre-defined formula as $\mathrm{Vt} /$ (plateau pressure- PEEP) with the plateau pressure being measured during the normal ventilation setting using an inspiratory pause at $10 \%$ of the inspiratory time. Both types of pulmonary compliance were recorded at $\mathrm{H}_{0}$ (after intubation), $\mathrm{H}_{1}$ (30 min after pneumoperitoneum), $\mathrm{H}_{2}$ (1 h after pneumoperitoneum), $\mathrm{H}_{3}$ (2 h after pneumoperitoneum), $\mathrm{H}_{\mathrm{kt}}$ (10 $\mathrm{min}$ after pneumoperitoneum stopped) and $\mathrm{H}_{\text {ro }}$ (before extubation). Pre- and postoperative (day 1 ) chest radiography at bedside was obtained and analyzed in a blinded way by a radiologist who was not involved in the study. Pathological chest X- 


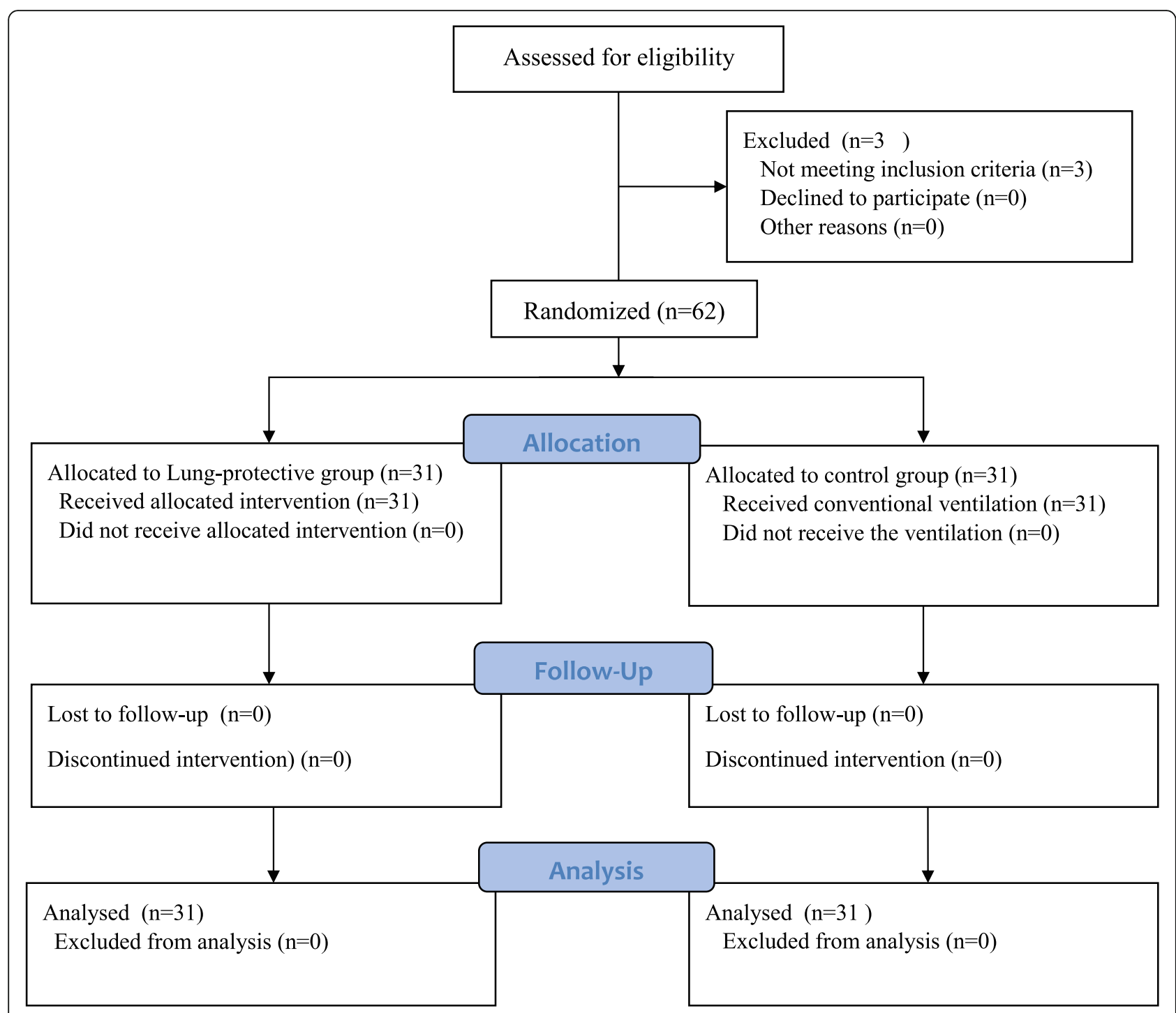

Fig. 1 Flow diagram of the process through the phases of the trial

ray was defined as the presence of at least one of the followings: an increase in the thickness of interstitium, atelectasis, pleural effusion, localized or diffuse infiltrates.

\section{Primary and secondary endpoints}

Our hypothesis was that the lung-protective ventilation could improve intraoperative oxygenation function, pulmonary mechanics, and early postoperative atelectasis. The primary endpoints were the intra- and postoperative changes in $\mathrm{P} / \mathrm{F}$. The secondary endpoints were the differences between the two groups regarding $\mathrm{PaO}_{2}, \mathrm{~A}-$ $\mathrm{aO}_{2}$; intraoperative $\mathrm{C}_{\text {dyn }}$ and $\mathrm{C}_{\text {stat }}$, and the incidence of atelectasis detected on chest $\mathrm{x}$-ray on the first postoperative day.

\section{Statistical analysis}

The sample size was calculated in accordance with the formula [25]: $\mathrm{n}=(2 \times \mathrm{C}) / \delta^{2}+1$ with $\delta=|\mu 1-\mu 2| / \sigma$, where $\mathrm{n}$ is the sample size in each group, $\mu 1=$ mean of $P / F$ in LPV group, $\mu 2=$ mean of $\mathrm{P} / \mathrm{F}$ in $\mathrm{CV}$ group, $\sigma$ is the common standard deviation and $\mathrm{c}=7.9$ for $80 \%$ power. The primary outcomes in the study of Xin Pi (2015) [26] showed that the $\mathrm{P} / \mathrm{F}$ after $2 \mathrm{~h}$ of ventilation in the two groups was $382.21 \pm$ 88.03 and $450.10 \pm 70.29$ respectively. Replacing $\mu 1=382.21$, $\mu 2=450.10, \sigma=88.03$ in the formula, $n$ was equal to 27.5 for each group. This represented that the minimum sample size for each group was at least 28 patients.

Statistical analysis was completed using SPSS software version 20.0 (IBM, USA) on an intention-to-treat basis. Whether variables distributed normally or not was tested 
Table 1 Patients demographic characteristics

\begin{tabular}{lll}
\hline & LPV group $(\boldsymbol{n}=\mathbf{3 1})$ & CV group $(\boldsymbol{n}=\mathbf{3 1})$ \\
\hline Age (year) & $59 \pm 9$ & $55 \pm 12$ \\
& $32-77$ & $29-74$ \\
Height $(\mathrm{cm})$ & $162[159-168]$ & $163[154-165]$ \\
Weight $(\mathrm{kg})$ & $53 \pm 8$ & $56 \pm 6$ \\
& $42-68$ & $40-72$ \\
IBW & $59[48-61]$ & $57[52-64]$ \\
BMI $\left(\mathrm{kg} \mathrm{m}{ }^{-2}\right)$ & $21 \pm 2$ & $21 \pm 3$ \\
& $18-26$ & $19-29$ \\
Gender (Female/male) (n) & $22 / 9$ & $18 / 13$ \\
ASA (I/II/III) (n) & $0 / 18 / 13$ & $0 / 20 / 11$ \\
History of smoking, $\mathrm{n}(\%)$ & $11(36)$ & $7(23)$ \\
History of hypertension & $6(19)$ & $4(13)$ \\
History of diabetes mellitus & $0(0)$ & $1(3)$ \\
\hline
\end{tabular}

Data are shown as mean $\pm S D$, median [interquartile range] and as percentage as appropriate. ASA American Society of Anesthesiologist, $B M I$ body mass index, IBW Ideal body weight. Differences among groups were not statistically significant

with the Kolmogorov-Smirnov and Shapiro-Wilk test. Continuous variables, depending on the characteristics of their distribution, were compared applying either Student's t-test or the Mann-Whitney U test, and consequently were reported as mean $\pm \mathrm{SD}$ or median and interquartile range (25-75\%) as appropriate. Comparisons of normally distributed variables were also performed with one-way ANOVA. As for categorical variables, the $X^{2}$ test was employed for comparison and the Fisher exact test was used for small frequencies. All the tests were two-tailed, and statistical significance was accepted at $p<0.05$.

\section{Results}

Sixty-five patients were initially assessed for eligibility. Three patients, including two with abnormalities on preoperative chest X-ray and one with a history of COPD, were excluded from the study. Therefore, 62 patients were randomly assigned to the two groups. The enrollment flow diagram is reported in Fig. 1. The demographic characteristics of the participants as well as the surgical and anesthesiological characteristics are presented in Tables 1 and 2, respectively.

\section{Gas exchange}

There were no significant differences regarding blood gas between the two groups before and after surgery. The intraoperative $\mathrm{PaO}_{2}$ and $\mathrm{P} / \mathrm{F}$ in LPV group were significantly higher than those in $\mathrm{CV}$ group $(p<0.05)$ (Table 3). The intraoperative $\mathrm{A}-\mathrm{aO}_{2}$ in LPV group was clearly lower than that in $\mathrm{CV}$ group, while the $\mathrm{PaCO}_{2}$ and $\mathrm{EtCO}_{2}$ during surgery in LPV group were higher than those in CV group $(p<0.05)$ (Table 3 and Fig. 2).

\section{Intraoperative pulmonary mechanics}

$\mathrm{C}_{\mathrm{dyn}}$ and $\mathrm{C}_{\text {stat }}$ at all the intraoperative time points in LPV group were significantly higher compared to CV group $(p<0.05)$ (Fig. 3 and 4$)$. The driving pressure at all investigated time points in LPV group were substantially lower than those in CV group $(p<0.05)$ (Fig. 5).

\section{Postoperative observations}

There were no differences in the chest X-ray, including the incidence of atelectasis, between the two groups on day one after surgery (Table 4). Length of stay in

Table 2 Surgical and anesthesiological characteristics

\begin{tabular}{|c|c|c|c|}
\hline & & LPV group $(n=31)$ & CV group $(n=31)$ \\
\hline \multirow[t]{5}{*}{ Types of surgery } & Gastrectomy & $10(32)$ & $7(23)$ \\
\hline & Colectomy & $6(19)$ & $12(38)$ \\
\hline & Miles' operation & $6(19)$ & $4(13)$ \\
\hline & LAR surgery & $7(23)$ & $6(19)$ \\
\hline & Others & $2(7)$ & $2(7)$ \\
\hline \multicolumn{2}{|c|}{ Duration of mechanical ventilation (minutes) } & $180[145-225]$ & 185 [155-220] \\
\hline \multicolumn{2}{|c|}{ Duration of pneumoperitoneum (minutes) } & $120[75-140]$ & $105[80-160]$ \\
\hline \multicolumn{2}{|c|}{ Intraoperative blood loss (ml) } & $110[75-140]$ & $130[90-160]$ \\
\hline \multicolumn{2}{|c|}{ Volume of crystalloid given (ml) } & $700[525-900]$ & 750 [525-900] \\
\hline \multicolumn{2}{|l|}{ Urine output (ml) } & 220 [170-220] & 200 [150-250] \\
\hline \multicolumn{2}{|c|}{ Total dose of propofol (mg) } & 100 [100-120] & $100[90-120]$ \\
\hline \multicolumn{2}{|c|}{ Total dose of fentanyl $(\mu \mathrm{g})$} & $350[300-350]$ & $350[300-350]$ \\
\hline \multicolumn{2}{|c|}{ Total dose of rocuronium (mg) } & $100[80-110]$ & $90[80-110]$ \\
\hline \multicolumn{2}{|c|}{ Postoperative VAS score } & $0[0-1]$ & $0[0-1]$ \\
\hline
\end{tabular}

Data are shown as median [interquartile range] or as percentage as appropriate. LAR Low anterior resection. Differences among groups were not statistically significant 
Table 3 perioperative arterial blood gas analysis

\begin{tabular}{|c|c|c|c|c|}
\hline & & LPV group $(n=31)$ & CV group $(n=31)$ & $p$ \\
\hline \multirow[t]{3}{*}{$\mathrm{PaO} 2(\mathrm{mmHg})$} & Preoperation & 86 [78-91] & 84 [79-95] & 0.2 \\
\hline & $1 \mathrm{~h}$ after pneumoperitoneum & 207 [193-225] & 189 [148-206] & 0.001 \\
\hline & 1 day after surgery & 98 [81-173] & $91[77-136]$ & 0.4 \\
\hline \multirow[t]{3}{*}{$\mathrm{PaCO} 2(\mathrm{mmHg})$} & Preoperation & 35 [34-39] & 37 [35-39] & 0.07 \\
\hline & $1 \mathrm{~h}$ after pneumoperitoneum & $\begin{array}{l}47 \pm 9 \\
36-62\end{array}$ & $\begin{array}{l}43 \pm 6 \\
31-56\end{array}$ & 0.03 \\
\hline & 1 day after surgery & $\begin{array}{l}38 \pm 5 \\
30-49\end{array}$ & $\begin{array}{l}38 \pm 4 \\
31-46\end{array}$ & 0.7 \\
\hline \multirow[t]{3}{*}{$\mathrm{PH}$} & Preoperation & $7.44[7.42-7.47]$ & $7.44[7.43-7.45]$ & 0.7 \\
\hline & $1 \mathrm{~h}$ after pneumoperitoneum & 7.37 [7.30-7.40] & $7.37[7.34-7.41]$ & 0.1 \\
\hline & 1 day after surgery & $\begin{array}{l}7.42 \pm 0.03 \\
7.35-7.48\end{array}$ & $\begin{array}{l}7.41 \pm 0.03 \\
7.36-7.46\end{array}$ & 0.1 \\
\hline \multirow[t]{3}{*}{$P / F$} & Preoperation & $\begin{array}{l}392 \pm 58 \\
316-466\end{array}$ & $\begin{array}{l}405 \pm 50 \\
330-473\end{array}$ & 0.3 \\
\hline & $1 \mathrm{~h}$ after pneumoperitoneum & $518[483-563]$ & $473[370-515]$ & 0.001 \\
\hline & 1 day after surgery & 327 [300-524] & 319 [285-453] & 0.4 \\
\hline \multirow[t]{3}{*}{$\mathrm{A}-\mathrm{aO}_{2}$} & Preoperation & $\begin{array}{l}20 \pm 7 \\
9-31\end{array}$ & $\begin{array}{l}19 \pm 7 \\
10-32\end{array}$ & 0.4 \\
\hline & $1 \mathrm{~h}$ after pneumoperitoneum & $\begin{array}{l}20 \pm 15 \\
4-77\end{array}$ & $\begin{array}{l}55 \pm 27 \\
15-106\end{array}$ & $<0.001$ \\
\hline & 1 day after surgery & $\begin{array}{l}47 \pm 34 \\
10-110\end{array}$ & $\begin{array}{l}57 \pm 28 \\
10-105\end{array}$ & 0.3 \\
\hline
\end{tabular}

Data are shown as mean \pm SD or median [interquartile range] as appropriate

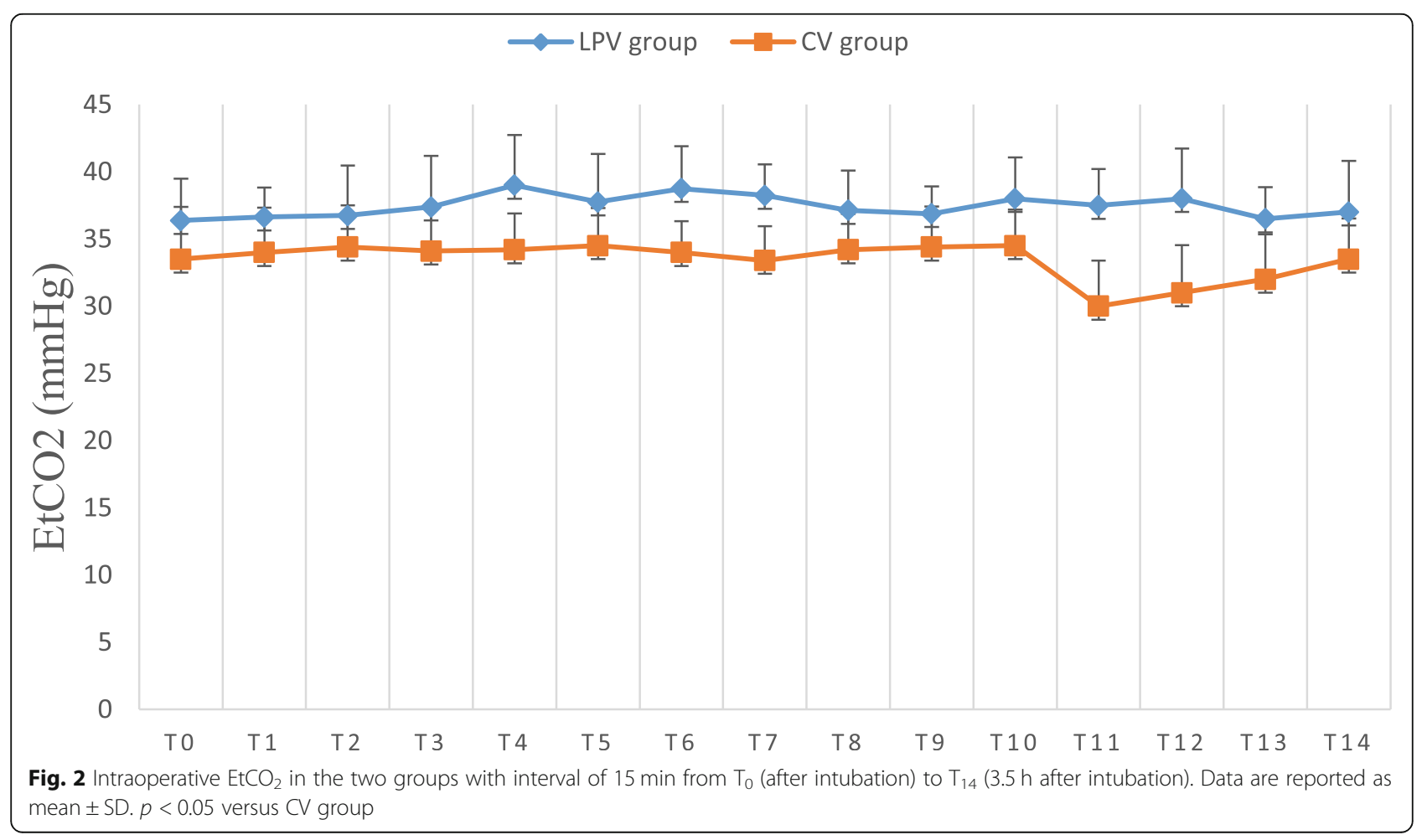




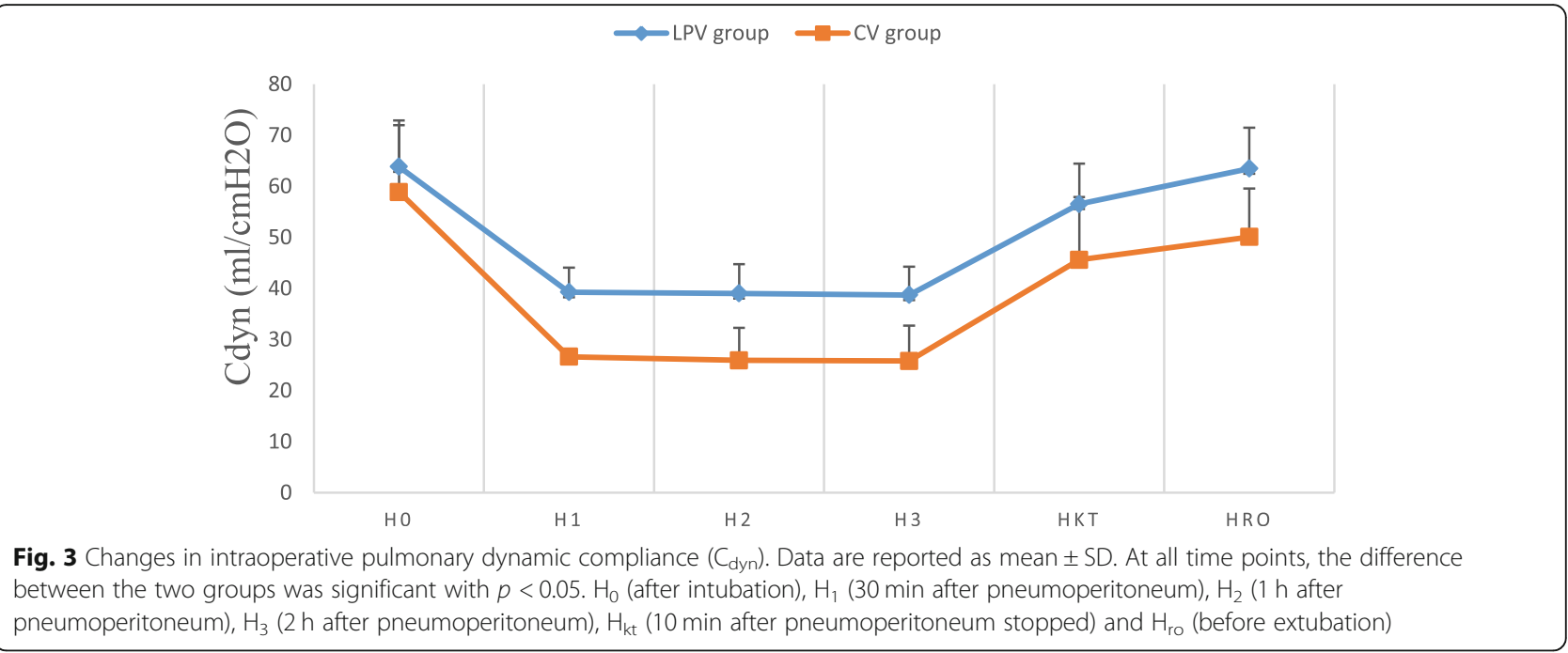

postoperative care unit was 2 days in both the LPV group and the CV group.

\section{Discussion}

The main findings of this randomized controlled trial were that in comparison to the conventional ventilation, the lung-protective ventilation with a low tidal volume (7 $\left.\mathrm{ml} \mathrm{kg}^{-1} \mathrm{IBW}\right), 10 \mathrm{cmH}_{2} \mathrm{O}$ PEEP, and RMs in laparoscopic surgery (1) improved intraoperative oxygenation, (2) increased pulmonary compliance, and reduced driving pressure, (3) did not show beneficial effects on oxygenation or atelectasis formation on the first day after surgery.

Several studies suggest that pulmonary oxygenation function is not significantly affected by abdominal $\mathrm{CO}_{2}$ insufflation [27, 28]. However, pneumoperitoneum, especially when prolonged, does predispose patients to decreased arterial oxygenation due to atelectasis and diminished functional residual capacity [29]. With the aim to minimize these consequences, our study show that the LPV improves pulmonary oxygenation during pneumoperitoneum. Explaining our endpoints, intraoperative periodic alveolar recruitment and continuous PEEP - two components of the LPV, has been demonstrated to be effective in improving arterial oxygenation $[30,31]$ by producing re-expansion and preventing the re-occurrence of atelectasis [29]. These theories were also re-confirmed by Whalen et al. (2006) [32] who, by employing an alveolar recruitment maneuver followed by $12 \mathrm{cmH}_{2} \mathrm{O}$ PEEP in morbidly obese patients, revealed that this strategy significantly enhanced intraoperative oxygenation. The oxygenation improvement also can be explained by an improvement of the ventilation perfusion matching induced by an appropriate level of PEEP. A previous studies, in which Electrical Impedance Tomograpy (EIT) was used to assess changes in regional

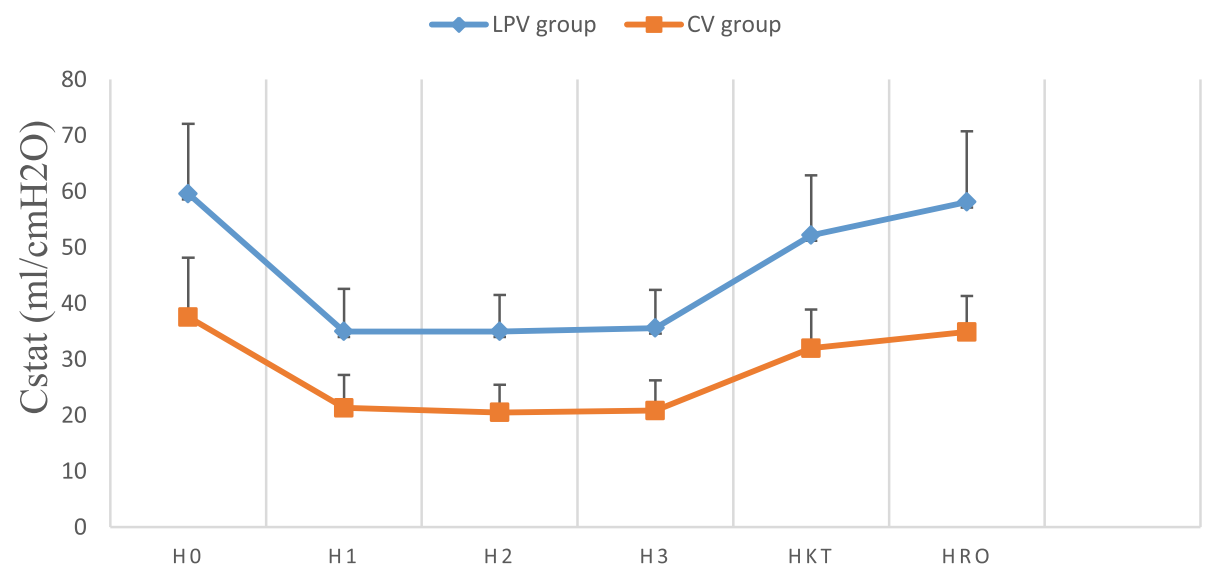

Fig. 4 Changes in intraoperative pulmonary static compliance $\left(C_{\text {stat }}\right)$. Data are reported as mean $\pm S D$. At all time points, the difference between the two groups was significant with $p<0.05 . \mathrm{H}_{0}$ (after intubation), $\mathrm{H}_{1}$ (30 min after pneumoperitoneum), $\mathrm{H}_{2}\left(1 \mathrm{~h}\right.$ after pneumoperitoneum), $\mathrm{H}_{3}(2$ $\mathrm{h}$ after pneumoperitoneum), $\mathrm{H}_{\mathrm{kt}}$ (10 min after pneumoperitoneum stopped) and $\mathrm{H}_{\mathrm{ro}}$ (before extubation) 


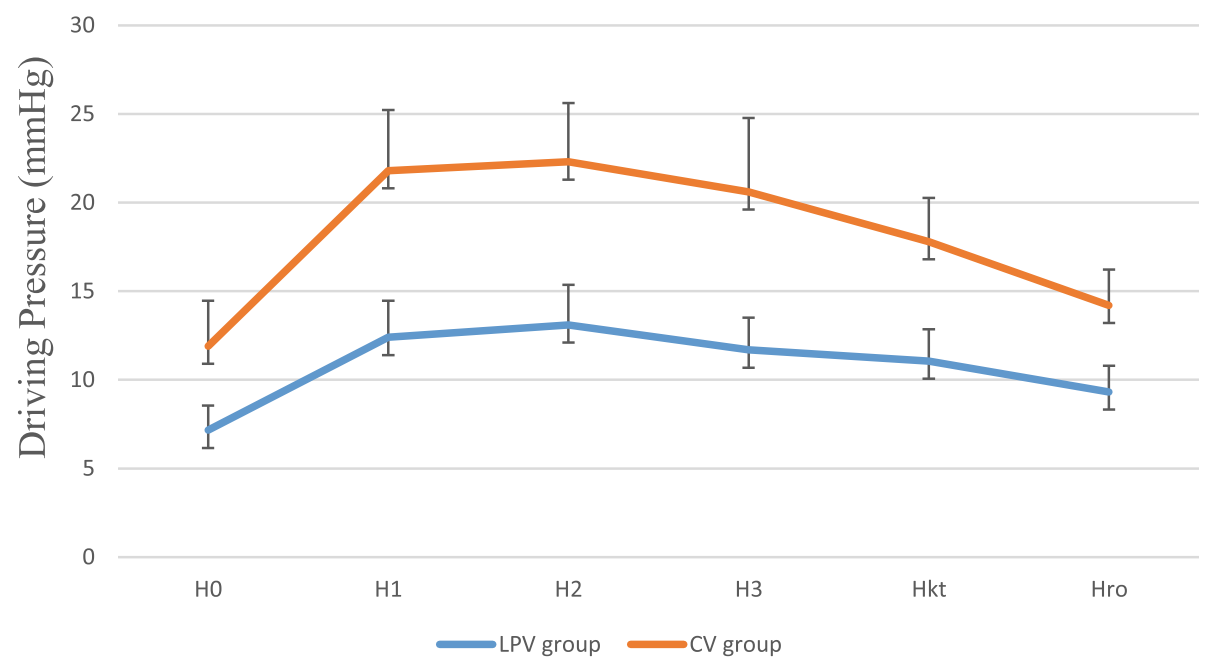

Fig. 5 Intraoperative driving pressure (DP) in the two groups. Data are reported as mean \pm SD. At all time points, the difference between the two groups was significant with $p<0.05 . \mathrm{H}_{0}$ (after intubation), $\mathrm{H}_{1}$ (30 min after pneumoperitoneum), $\mathrm{H}_{2}\left(1 \mathrm{~h}\right.$ after pneumoperitoneum), $\mathrm{H}_{3}(2 \mathrm{~h}$ after pneumoperitoneum), $\mathrm{H}_{\mathrm{kt}}$ (10 min after pneumoperitoneum stopped) and $\mathrm{H}_{\mathrm{ro}}$ (before extubation)

ventilation in patients undergoing laparoscopic cholecystectomy, showed that intraoperative PEEP $\left(10 \mathrm{cmH}_{2} \mathrm{O}\right)$ preserved a more homogeneous ventilation distribution, and hence resulting in a better ventilation perfusion matching as compared to zero PEEP intraoperatively or postoperatively [19].

Alveolar-arterial oxygen gradient $\left(\mathrm{A}-\mathrm{aO}_{2}\right)$ has clinical utility as its abnormally high values are associated with shunt, ventilation-perfusion mismatch and gas diffusion abnormalities across the alveolar-capillary membrane. Allen et al. described the $\mathrm{A}-\mathrm{aO}$ as a useful tool to evaluate intrapulmonary shunt caused by alveolar collapse [33]. In the present study, $\mathrm{A}-\mathrm{aO}_{2}$ during pneumoperitoneum, as a marker of shunting, was significantly lower in the LPV group compared to CV group. Similar finding was reported by Jing Liu (2019) [34]. The improved intraoperative oxygenation function in LPV group, however, was at the cost of elevation in $\mathrm{PaCO}_{2}$ and $\mathrm{EtCO}_{2}$, which may result from the low tidal volume. This hypercapnia seemed not to be harmful to patients since the $\mathrm{pH}$ was still kept in a normal range and the elevation of
$\mathrm{PaCO}_{2}$ was in line with permissive hypercapnia (the rate of increase in $\mathrm{PaCO}_{2} \leq 10 \mathrm{mmHg}$ per hour and the upper limit should not higher than $100 \mathrm{mmHg}$ ) [35].

Intraoperative pneumoperitoneum and Trendelenburg positioning in laparoscopic surgery have been demonstrated to facilitate atelectasis formation $[4,36,37]$ by shifting the diaphragm cranially [27, 38], thereby decreasing pulmonary compliance, leading to collapse of small airways and alveoli [26]. To exemplify this point, Gilda Cinnella (2013) showed that intraoperative pneumoperitoneum and Trendelenburg position worsened respiratory mechanics (increase in lung elastance, static intrinsic PEEP, and total airway resistances) [17]. Dealing with this phenomenon, our study showed that the LPV strategy could partially reverse the deleterious effects of pneumoperitoneum and Trendelenburg position on pulmonary mechanics by decreasing atelectasis and improving dynamic and static compliance before, during, and after pneumoperitoneum. For an explanation of this result, we speculated that the high level of PEEP following the RMs could partially counterbalance the cranial shift

Table 4 Pathological chest $X$-ray test on the postoperative day 1

\begin{tabular}{|c|c|c|c|c|c|}
\hline & \multicolumn{2}{|c|}{ LPV group $(n=31)$} & \multicolumn{2}{|c|}{ CV group $(n=31)$} & \multirow[t]{2}{*}{$p$} \\
\hline & $n$ & $\%$ & $\mathrm{n}$ & $\%$ & \\
\hline Normal & 21 & 67.7 & 20 & 64.5 & 0.7 \\
\hline Increased thickness of interstitium & 5 & 16.1 & 5 & 16.1 & \\
\hline Atelectasis & 0 & 0 & 2 & 6.5 & \\
\hline Diffuse infiltrate & 2 & 6.5 & 2 & 6.5 & \\
\hline Localized infiltrate & 3 & 9.7 & 1 & 3.2 & \\
\hline Pleural effusion & 0 & 0 & 1 & 3.2 & \\
\hline
\end{tabular}


of the diaphragm caused by pneumoperitoneum and could induce the corresponding lung expansion. Moreover, PEEP keeps the alveoli open and prevent them from repeated opening and collapse [33], which may, over a long ventilation period, lead to pulmonary injury [26]. However, the use of a high level of PEEP intraoperatively posed a significant concern about barotrauma in normal lung and hence may be associated with lung injuries [39]. The level of PEEP in our study should be well tolerated since the driving pressure in LPV group was kept quite low $\left(<15 \mathrm{cmH}_{2} \mathrm{O}\right)$ (Fig. 5) and significantly lower than those in CV group. A cohort study in 2019, in which 1913 patients undergoing cardiac surgery were provided with a protective ventilation bundle comprising of $\mathrm{Vt}<8 \mathrm{ml} / \mathrm{kg}$ IBW, modified driving pressure $<16$ $\mathrm{cmH}_{2} \mathrm{O}$, and PEEP $\geq 5 \mathrm{cmH}_{2} \mathrm{O}$, revealed that the modified driving pressure was independently associated with decreased PPCs (OR 0.51, 95\% CI, 0.39 to 0.66 ), but Vt $<$ $8 \mathrm{ml} / \mathrm{kg}$ and PEEP $\geq 5 \mathrm{cmH}_{2} \mathrm{O}$ were not [40].

Atelectasis develops in as much as $90 \%$ of patients undergoing general anesthesia [41] and can persist to different degrees after surgery. The etiologies of atelectasis formation during intraoperative short-term ventilation in normal lungs are the compression of lung parenchyma [42], reabsorption of intraalveolar gas [43, 44], collapse of small airways [45], and surfactant dysfunction. The unventilated lung areas are more likely to occur near to the diaphragm with an estimated incidence of 3 to $6 \%[46,47]$ to 20 to $25 \%$ [41]. The incidence of atelectasis in our study was fairly low (2 patients occupied $6.5 \%$ in $\mathrm{CV}$ group) and there was no significant difference between the two groups. One of the limitations in our study was that chest $\mathrm{x}$-ray is much less sensible as compared to CT scanner with regard to atelectatic detection. For this reason, we could not identify pentients with low levels of atelectasis.

There were some limitations to our study. Firstly, our trial considered intraoperative protective mechanical ventilation using bundles of interventions which included a low tidal volume, a high level of PEEP, accompanied by periodic lung recruitment maneuvers. It is difficult to determine the role of each component and to conclude which provided the benefits: the decrease in tidal volume, or the high level of PEEP or the recruitment maneuvers or both. Moreover, to what extent low tidal volumes succeeded in preventing barotrauma and volutrauma could not be analyzed. Secondly, the degree of PEEP should be titrated individually. Several factors that affect individual titration of PEEP during general anesthesia are (1) the respiratory system mechanics [17], (2) oxygenation target [12], (3) level of EELV [48], and (4) distribution of ventilation using electric impedance tomography [19, 49]. Thus, $10 \mathrm{cmH}_{2} \mathrm{O}$ PEEP in our study may not be suitable for all patients. Thirdly, compared with computed tomography, chest X-ray reportedly underestimate the occurrence of atelectasis and pulmonary morphological alterations [50].

\section{Conclusion}

Lung-protective mechanical ventilation consisting of a low tidal volume of $7 \mathrm{ml} \mathrm{kg}^{-1}$ IBW, $10 \mathrm{cmH}_{2} \mathrm{O}$ PEEP and regular recruitment maneuvers in abdominal laparoscopic surgeries can significantly improve intraoperative oxygenation function, pulmonary compliance, but can not prevent early postoperative atelectasis formation on the first day after surgery. Larger sample size and longterm evaluation are recommended for future studies.

\section{Abbreviations \\ LPV: Lung-protective ventilation; VILI: Ventilator-induced lung injury; Vt: Tidal volume; PEEP: Positive end-expiratory pressure; RMs: Recruitment maneuvers; IBW: Ideal body weight; CV: Conventional ventilation; $C_{\text {dyn: }}$ : Dynamic compliance; $\mathrm{C}_{\text {stat: }}$ Static compliance; P/F: The ratio of $\mathrm{PaO}_{2}$ to $\mathrm{FiO}_{2} ; \mathrm{A}$ - $\mathrm{aO}_{2}$ : Alveolar-arterial oxygen gradient; $\mathrm{mCPIS}$ : Modified clinical pulmonary infection score; PPCs: Postoperative pulmonary complications; EELV: End- expiratory lung volume; ASA: American society of anesthesiologists; BMI: Body mass index; PPV: Pulse pressure variation; VAS: Visual analogue scale; $\mathrm{EtCO}_{2}$ : End-tidal carbon dioxide; PRST: Pressure, rate, sweating, tears}

\section{Acknowledgments}

Assistance with the study: we would like to thank our patients and all the clinical and research staff in the Department of Anesthesia and Pain Medicine at Vietnam National Cancer Hospital who made the trial possible.

\section{Authors' contributions}

T.K.N was responsible for the study concept and design. T.A.V and A.N.L. wrote the manuscript. V.L.N, T.G.N, D.H.M, N.Q.N, Q.H.N, C.T.N and D.T.N participated in the collection and interpretation of the data. All authors approved the final version of the manuscript.

\section{Funding}

There are no grants and financial support to declare.

\section{Availability of data and materials}

The datasets used and/or analyzed during this study are available from the corresponding author on reasonable request.

\section{Declarations}

\section{Ethics approval and consent to participate}

This single-centre, prospective randomized controlled study was conducted at Vietnam National Cancer Hospital from January 2020 to July 2020. The trial protocol was approved by the Medical Ethics Committee of Vietnam National Cancer Hospital and Vietnam Military Medical University (QĐ-HVQY 264-2020; chairperson Prof Truong Giang Nguyen; on 10 January 2020). The protocol was also registered in ClinicalTrial.gov Protocol Registration and Results System (NCT04546932). The trial was performed according to the Declaration of Helsinki. Also of important, written informed consent was simultaneously obtained from all patients before inclusion. Our study complies with the Consolidated Standards of Reporting Trials (CONSORT) guidelines (CONSORT Checklist); a CONSORT flow chart is presented in Fig. 1.

\section{Consent for publication}

Not applicable.

\section{Competing interests}

No author has any conflict of interest regarding the publication of this article. 


\section{Author details}

'Center of Emergency, Critical Care Medicine and Clinical Toxicology, 103 Military Hospital, Vietnam Military Medical University, 261 Phung Hung road, Ha Dong District, Hanoi City, Vietnam. ${ }^{2}$ Critical Care Unit, National Burn Hospital, Vietnam Military Medical University, Hanoi, Vietnam. ${ }^{3}$ Department of Cardiothoracic surgery, 103 Military Hospital, Vietnam Military Medical University, Hanoi, Vietnam. ${ }^{4}$ Department of Anesthesia and Pain Medicine, 103 Military Hospital, Vietnam Military Medical University, Hanoi, Vietnam. ${ }^{5}$ Department of Anesthesia and Pain Medicine, Vietnam National Cancer Hospital, Hanoi, Vietnam. ${ }^{6}$ Department of Urology, 103 Military Hospital, Vietnam Military Medical University, Hanoi, Vietnam.

Received: 31 October 2020 Accepted: 17 March 2021 Published online: 30 March 2021

\section{References}

1. Duggan M, Kavanagh BP. Pulmonary atelectasis: a pathogenic perioperative entity. Anesthesiology. 2005;102(4):838-54.

2. Magnusson L, Spahn DR. New concepts of atelectasis during general anaesthesia. Br J Anaesth. 2003;91(1):61-72.

3. Grasso S, Terragni P, Mascia L, Fanelli V, Quintel M, Herrmann P, et al. Airway pressure-time curve profile (stress index) detects tidal recruitment/ hyperinflation in experimental acute lung injury. Crit Care Med. 2004;32(4): 1018-27.

4. Hedenstierna $G$, Edmark $L$. The effects of anesthesia and muscle paralysis on the respiratory system. Intensive Care Med. 2005;31(10):1327-35.

5. Reinius $H$, Jonsson L, Gustafsson S, Sundbom M, Duvernoy O, Pelosi P, et al. Prevention of atelectasis in morbidly obese patients during general anesthesia and paralysis: a computerized tomography study. Anesthesiology. 2009;111(5):979-87.

6. Choi G, Wolthuis EK, Bresser P, Levi M, van der Poll T, Dzoljic M, et al. Mechanical ventilation with lower tidal volumes and positive end-expiratory pressure prevents alveolar coagulation in patients without lung injury. Anesthesiology. 2006;105(4):689-95.

7. Wolthuis EK, Choi G, Dessing MC, Bresser P, Lutter R, Dzoljic M, et al. Mechanical ventilation with lower tidal volumes and positive end-expiratory pressure prevents pulmonary inflammation in patients without preexisting lung injury. Anesthesiology. 2008;108(1):46-54.

8. Tusman G, Bohm SH, Warner DO, Sprung J. Atelectasis and perioperative pulmonary complications in high-risk patients. Curr Opin Anaesthesiol. 2012; 25(1):1-10.

9. Jaber S, Coisel Y, Chanques G, Futier E, Constantin JM, Michelet P, et al. A multicentre observational study of intra-operative ventilatory management during general anaesthesia: tidal volumes and relation to body weight. Anaesthesia. 2012;67(9):999-1008.

10. Haliloglu M, Bilgili B, Ozdemir M, Umuroglu T, Bakan N. Low tidal volume positive end-expiratory pressure versus high tidal volume zero-positive endexpiratory pressure and postoperative pulmonary functions in robot-assisted laparoscopic radical prostatectomy. Med Princ Pract. 2017;26(6):573-8.

11. Hansen JK, Anthony DG, Li L, Wheeler D, Sessler DI, Bashour CA Comparison of positive end-expiratory pressure of 8 versus $5 \mathrm{~cm} \mathrm{H} 2 \mathrm{O}$ on outcome after cardiac operations. J Intensive Care Med. 2015;30(6):338-43.

12. Reis Miranda D, Gommers D, Struijs A, Dekker R, Mekel J, Feelders R, et al. Ventilation according to the open lung concept attenuates pulmonary inflammatory response in cardiac surgery. Eur J Cardiothorac Surg. 2005; 28(6):889-95.

13. Tusman G, Bohm SH, Suarez-Sipmann F, Turchetto E. Alveolar recruitment improves ventilatory efficiency of the lungs during anesthesia. Can J Anaesth. 2004;51(7):723-7.

14. Futier E, Constantin JM, Paugam-Burtz C, Pascal J, Eurin M, Neuschwander A, et al. A trial of intraoperative low-tidal-volume ventilation in abdominal surgery. N Engl J Med. 2013;369(5):428-37.

15. Maracaja-Neto LF, Vercosa N, Roncally AC, Giannella A, Bozza FA, Lessa MA. Beneficial effects of high positive end-expiratory pressure in lung respiratory mechanics during laparoscopic surgery. Acta Anaesthesiol Scand. 2009;53(2): 210-7.

16. Pelosi P, Ravagnan I, Giurati G, Panigada M, Bottino N, Tredici S, et al. Positive end-expiratory pressure improves respiratory function in obese but not in normal subjects during anesthesia and paralysis. Anesthesiology. 1999;91(5):1221-31.
17. Cinnella G, Grasso S, Spadaro S, Rauseo M, Mirabella L, Salatto P, et al. Effects of recruitment maneuver and positive end-expiratory pressure on respiratory mechanics and transpulmonary pressure during laparoscopic surgery. Anesthesiology. 2013;118(1):114-22.

18. Bouadma L, Dreyfuss D, Ricard JD, Martet G, Saumon G. Mechanical ventilation and hemorrhagic shock-resuscitation interact to increase inflammatory cytokine release in rats. Crit Care Med. 2007;35(11):2601-6.

19. Karsten J, Luepschen H, Grossherr M, Bruch HP, Leonhardt S, Gehring H, et al. Effect of PEEP on regional ventilation during laparoscopic surgery monitored by electrical impedance tomography. Acta Anaesthesiol Scand. 2011;55(7):878-86.

20. Marik PE, Cavallazzi R, Vasu T, Hirani A. Dynamic changes in arterial waveform derived variables and fluid responsiveness in mechanically ventilated patients: a systematic review of the literature. Crit Care Med. 2009:37(9):2642-7.

21. Cannesson M, Le Manach Y, Hofer CK, Goarin JP, Lehot JJ, Vallet B, et al. Assessing the diagnostic accuracy of pulse pressure variations for the prediction of fluid responsiveness: a "gray zone" approach. Anesthesiology. 2011:115(2):231-41.

22. Biais M, de Courson H, Lanchon R, Pereira B, Bardonneau G, Griton M, et al. Mini-fluid challenge of $100 \mathrm{ml}$ of crystalloid predicts fluid responsiveness in the operating room. Anesthesiology. 2017;127(3):450-6.

23. Yu AL, Cai XZ, Gao XJ, Zhang ZW, Ma ZS, Ma LL, et al. Determinants of immediate extubation in the operating room after total thoracoscopic closure of congenital heart defects. Med Princ Pract. 2013;22(3):234-8.

24. Sprung J, Whalen FX, Comfere T, Bosnjak ZJ, Bajzer Z, Gajic O, et al. Alveolar recruitment and arterial desflurane concentration during bariatric surgery. Anesth Analg. 2009:108(1):120-7.

25. Chan YH. Randomised controlled trials (RCTs)--sample size: the magic number? Singap Med J. 2003;44(4):172-4.

26. Pi X, Cui Y, Wang C, Guo L, Sun B, Shi J, et al. Low tidal volume with PEEP and recruitment expedite the recovery of pulmonary function. Int J Clin Exp Pathol. 2015;8(11):14305-14.

27. Sprung J, Whalley DG, Falcone T, Wilks W, Navratil JE, Bourke DL. The effects of tidal volume and respiratory rate on oxygenation and respiratory mechanics during laparoscopy in morbidly obese patients. Anesth Analg. 2003;97(1):268-74 table of contents.

28. Sprung J, Whalley DG, Falcone T, Warner DO, Hubmayr RD, Hammel J. The impact of morbid obesity, pneumoperitoneum, and posture on respiratory system mechanics and oxygenation during laparoscopy. Anesth Analg. 2002;94(5):1345-50

29. Hazebroek EJ, Haitsma JJ, Lachmann B, Bonjer HJ. Mechanical ventilation with positive end-expiratory pressure preserves arterial oxygenation during prolonged pneumoperitoneum. Surg Endosc. 2002;16(4):685-9.

30. Tusman G, Bohm SH, De Anda GV, do Campo JL, Lachmann B. 'Alveolar recruitment strategy' improves arterial oxygenation during general anaesthesia. Br J Anaesth. 1999:82(1):8-13.

31. Pang CK, Yap J, Chen PP. The effect of an alveolar recruitment strategy on oxygenation during laparascopic cholecystectomy. Anaesth Intensive Care. 2003;31(2):176-80.

32. Whalen FX, Gajic O, Thompson GB, Kendrick ML, Que FL, Williams BA, et al. The effects of the alveolar recruitment maneuver and positive endexpiratory pressure on arterial oxygenation during laparoscopic bariatric surgery. Anesth Analg. 2006:102(1):298-305.

33. Allen SJ. In: Hoyt JW, editor. AS. T. Advances in respiratory life support. Philadelphia: WB Saunders; 1991.

34. Liu J, Meng Z, Lv R, Zhang Y, Wang G, Xie J. Effect of intraoperative lungprotective mechanical ventilation on pulmonary oxygenation function and postoperative pulmonary complications after laparoscopic radical gastrectomy. Braz J Med Biol Res. 2019;52(6):e8523.

35. Feihl F, Perret C. Permissive hypercapnia. How permissive should we be? Am J Respir Crit Care Med. 1994;150(6 Pt 1):1722-37.

36. Valenza F, Chevallard G, Fossali T, Salice V, Pizzocri M, Gattinoni L. Management of mechanical ventilation during laparoscopic surgery. Best Pract Res Clin Anaesthesiol. 2010;24(2):227-41.

37. Strang CM, Hachenberg T, Freden F, Hedenstierna G. Development of atelectasis and arterial to end-tidal PCO2-difference in a porcine model of pneumoperitoneum. Br J Anaesth. 2009;103(2):298-303.

38. Perilli V, Sollazzi L, Bozza P, Modesti C, Chierichini A, Tacchino RM, et al. The effects of the reverse trendelenburg position on respiratory mechanics and blood gases in morbidly obese patients during bariatric surgery. Anesth Analg. 2000;91(6):1520-5. 
39. Hong CM, Xu DZ, Lu Q, Cheng Y, Pisarenko V, Doucet D, et al. Low tidal volume and high positive end-expiratory pressure mechanical ventilation results in increased inflammation and ventilator-associated lung injury in normal lungs. Anesth Analg. 2010;110(6):1652-60.

40. Mathis MR, Duggal NM, Likosky DS, Haft JW, Douville NJ, Vaughn MT, et al. Intraoperative mechanical ventilation and postoperative pulmonary complications after cardiac surgery. Anesthesiology. 2019;131(5):1046-62.

41. Lundquist H, Hedenstierna G, Strandberg A, Tokics L, Brismar B. CTassessment of dependent lung densities in man during general anaesthesia. Acta Radiol. 1995;36(6):626-32.

42. Pelosi P, Goldner M, McKibben A, Adams A, Eccher G, Caironi P, et al. Recruitment and derecruitment during acute respiratory failure: an experimental study. Am J Respir Crit Care Med. 2001;164(1):122-30.

43. Joyce CJ, Williams AB. Kinetics of absorption atelectasis during anesthesia: a mathematical model. J Appl Physiol (1985). 1999:86(4):1116-25.

44. Rothen HU, Sporre B, Engberg G, Wegenius G, Hogman M, Hedenstierna G. Influence of gas composition on recurrence of atelectasis after a reexpansion maneuver during general anesthesia. Anesthesiology. 1995; 82(4):832-42.

45. Juno J, Marsh HM, Knopp TJ, Rehder K. Closing capacity in awake and anesthetized-paralyzed man. J Appl Physiol Respir Environ Exerc Physiol. 1978:44(2):238-44.

46. Cai $H$, Gong H, Zhang L, Wang Y, Tian Y. Effect of low tidal volume ventilation on atelectasis in patients during general anesthesia: a computed tomographic scan. J Clin Anesth. 2007;19(2):125-9.

47. Rusca M, Proietti S, Schnyder P, Frascarolo P, Hedenstierna G, Spahn DR, et al. Prevention of atelectasis formation during induction of general anesthesia. Anesth Analg. 2003;97(6):1835-9.

48. Satoh D, Kurosawa S, Kirino W, Wagatsuma T, Ejima Y, Yoshida A, et al. Impact of changes of positive end-expiratory pressure on functional residual capacity at low tidal volume ventilation during general anesthesia. J Anesth. 2012;26(5):664-9.

49. Zhao Z, Guttmann J, Moller K. Adaptive SLICE method: an enhanced method to determine nonlinear dynamic respiratory system mechanics. Physiol Meas. 2012;33(1):51-64

50. Gregoretti C, Pelosi P. A physiologically oriented approach to the perioperative period: the role of the anaesthesiologist. Best Pract Res Clin Anaesthesiol. 2010;24(2):vii-viii.

\section{Publisher's Note}

Springer Nature remains neutral with regard to jurisdictional claims in published maps and institutional affiliations.

Ready to submit your research? Choose BMC and benefit from:

- fast, convenient online submission

- thorough peer review by experienced researchers in your field

- rapid publication on acceptance

- support for research data, including large and complex data types

- gold Open Access which fosters wider collaboration and increased citations

- maximum visibility for your research: over $100 \mathrm{M}$ website views per year

At $\mathrm{BMC}$, research is always in progress.

Learn more biomedcentral.com/submissions 